\title{
Heterogeneous location of the mupA high-level mupirocin resistance gene in Staphylococcus aureus
}

\author{
N. WOODFORD, A. P. WATSON, SUNITA PATEL, M. JEVON, D. J. WAGHORN* and \\ B. D. COOKSON \\ Laboratory of Hospital Infection, Central Public Health Laboratory, London NW9 5HT and *Department of \\ Microbiology, Wycombe General Hospital, High Wycombe HP11 2TT
}

\begin{abstract}
Epidemiologically unrelated clinical isolates of Staphylococcus aureus with high-level resistance to mupirocin (MIC $\geqslant 512 \mathrm{mg} / \mathrm{L}$ ) were studied to determine the location of the mup $A$ resistance gene. The gene was carried on plasmids of variable size, some of which were transferable in vitro. DNA hybridisation of genomic DNA from 85 isolates showed that mupA was located on EcoR I fragments of seven different sizes; the most frequently observed fragments were $7 \mathrm{~kb}$ (46 isolates) or $4.1 \mathrm{~kb}$ ( 21 isolates). All isolates retained a 1.6-kb $N$ co I fragment that hybridised with mupA probes, but showed heterogeneous hybridisation patterns after digestion with Hinc II. These data suggested that mupA may be conserved, but that variation occurs in the flanking DNA proximal to it. Amplification of spacer regions between mupA and closest proximal copy of IS257 yielded products of variable size and was consistent with the presence of IS257 in either orientation. It is proposed that IS257-mediated events are responsible for the heterogeneity observed. The location of $m u p A$ varied between epidemiologically unrelated isolates of the same strain, including isolates of EMRSA-16 - one of the two predominant methicillin-resistant strains in UK hospitals at the present time - and this correlated with variations in the digestion patterns of the mupirocin resistance plasmids. The variable location of mupA should be evaluated further as a potential epidemiological tool with which to monitor the spread of high-level mupirocin resistance in EMRSA-16 or other strains of $S$. aureus.
\end{abstract}

\section{Introduction}

Mupirocin is an antibiotic used topically for the treatment of staphylococcal and streptococcal skin infections and for the eradication of carriage of Staphylococcus aureus, including strains resistant to methicillin (MRSA). High-level, transferable resistance to mupirocin (MIC $\geqslant 512 \mathrm{mg} / \mathrm{L}$ ) [1] was first reported among clinical isolates of $S$. aureus from a London hospital [2] and abrogates the effective clinical use of the agent. This form of resistance is encountered increasingly in the UK, particularly in the south-east of England, and is exhibited by both methicillin-sensitive and -resistant $S$. aureus. In particular, its association with various epidemic strains of MRSA (EMRSA) may cause serious infection control problems [3].

Received 20 Oct. 1997; revised version accepted 13 Jan. 1998.

Corresponding author: Dr B. D. Cookson.
High-level mupirocin resistance results from the acquisition of new DNA which encodes production of a mupirocin-resistant isoleucyl tRNA synthetase [1]. In the presence of mupirocin, this enzyme takes over the function of the sensitive chromosomal enzyme. The resistance gene has been cloned [4], sequenced [5] and probes have been used to investigate its distribution. It has been designated variously ileS [5], ileS-2 [6] or mupA [7]. Hereafter, it will be referred to as mup $A$. This gene is carried on diverse plasmids, although plasmids in epidemiologically related isolates may appear similar [8]. However, despite this diversity of plasmids, the mupA gene is located on an $c .4-\mathrm{kb}$ EcoR I DNA fragment in all but three high-level mupirocin-resistant isolates of $S$. aureus and coagulase-negative staphylococci examined previously [912]. This homogeneous pattern of hybridisation in staphylococci from diverse sources is consistent with the dissemination of a conserved resistance transposon of which the mupA gene is a part $[10,11]$. The present study examined the location of the mupA 
mupirocin resistance gene in $S$. aureus isolated in the UK since 1990.

\section{Materials and methods}

\section{Bacterial isolates}

Eighty-five clinical isolates of $S$. aureus with high-level resistance to mupirocin ( $\mathrm{MIC} \geqslant 512 \mathrm{mg} / \mathrm{L}$ ) were included in this study. In the initial investigations, 15 isolates from different centres were chosen to represent various strains causing current problems in UK hospitals (Table 1). These were five epidemiologically distinct isolates of EMRSA-16 (including the first high-level mupirocin-resistant isolate of this strain from 1993), two isolates of EMRSA-3, two other non-epidemic MRSA strains (OMRSA) and six isolates of a mecA-negative strain with intermediate methicillin resistance (MIC 4$8 \mathrm{mg} / \mathrm{L}$, IMRSA) [3]. In addition, isolates 'STH 1' and 'Bristol 3', both of which had been shown previously to hybridise with a mupirocin resistance probe [10,11], were included as controls for hybridisation and PCR studies. Subsequently, studies were extended to include 16 isolates of EMRSA-16 referred from different UK hospitals during 1995 and $52 \mathrm{~S}$. aureus isolates referred from a single UK centre since 1991. Isolates from this latter centre represented numerous phage types and were mainly methicillin-sensitive isolates from patients prescribed mupirocin in the community and referred by their general practitioners to outpatient clinics.

\section{Transfer studies and plasmid analysis}

Transfer of mupirocin resistance from 17 isolates (Table 1) was investigated by a semi-quantitative filter mating technique. Overnight cultures of potential donor isolates and the $S$. aureus recipient strain WG3358 [13] were suspended in nutrient broth. Equal volumes $(100 \mu \mathrm{l})$ of the suspensions of each donor and the recipient were mixed on a sterile filter $(0.45-\mu \mathrm{m}$ pore size) on a nutrient agar plate and incubated overnight. Growth on the filters was harvested into $1 \mathrm{ml}$ of nutrient broth and $100-\mu 1$ samples were plated on to Brain Heart Infusion (BHI; Unipath) Agar containing rifampicin (Sigma) $25 \mathrm{mg} / \mathrm{L}$ and novobiocin (Sigma) $5 \mathrm{mg} / \mathrm{L}$, together with either mupirocin (SmithKline Beecham Pharmaceuticals) $50 \mathrm{mg} / \mathrm{L}$ or gentamicin (Sigma) $4 \mathrm{mg} / \mathrm{L}$. All donor and recipient cultures were also plated on to this selective medium as controls and incubated at $37^{\circ} \mathrm{C}$ for $24-48 \mathrm{~h}$. Putative transconjugant colonies were subcultured on selective agar once before further non-selective passages. Plasmids were extracted from donors and transconjugants by Brij lysis [14] or, when digestion with restriction endonucleases was required, with cetyltrimethylammonium bromide (CTAB) [13]. DNA was separated on agarose $0.8 \%$ gels at $90 \mathrm{~V}$ for $2-3 \mathrm{~h}$ in $0.5 \times \mathrm{TBE}$ buffer $(1 \times \mathrm{TBE}$ is $89 \mathrm{mM}$ Tris, $89 \mathrm{mM}$ boric acid, $2 \mathrm{mM}$ EDTA, pH 8) and stained with ethidium bromide $(1 \mathrm{mg} / \mathrm{L})$ before being viewed under UV light. The plasmids were transferred to Hybond-N membrane (Amersham) by a VacuGene blotter (Pharmacia-LKB) and fixed at $80^{\circ} \mathrm{C}$ for $2 \mathrm{~h}$; these blots were stored at room temperature until required for hybridisation studies.

\section{Extraction of genomic DNA}

Genomic DNA was prepared from isolates of $S$. aureus with guanidium thiocyanate [15] and 5- $\mu \mathrm{g}$ samples were digested overnight with $10 \mathrm{U}$ of Eco RI, Hinc II or Nco I (Life Technologies). Digested DNA was electrophoresed through agarose $0.8 \%$ gels at $25 \mathrm{~V}$ for $16 \mathrm{~h}$ in $0.5 \times \mathrm{TBE}$ buffer and blotted to nylon membrane as above.

\section{DNA probes for mupA and hybridisation studies}

Two digoxigenin-labelled probes specific for the mupA high-level mupirocin resistance gene were used in this investigation (Fig. 1). Probe A consisted of an intragenic

Table 1. High-level mupirocin-resistance in diverse S.aureus isolates from 17 UK hospitals

\begin{tabular}{|c|c|c|c|c|c|}
\hline Isolate & $\begin{array}{l}\text { Year of } \\
\text { isolation }\end{array}$ & Strain & $\begin{array}{c}\text { Size of } \mathrm{Mu}^{\mathrm{r}} \\
\text { Plasmid (MDa) }\end{array}$ & $\begin{array}{c}\text { Transfer of } \mathrm{Mu}^{\mathrm{r}} \\
\text { in vitro }\end{array}$ & $\begin{array}{l}\text { Size of mupA-bearing } \\
\text { EcoR I fragment }(\mathrm{kb})\end{array}$ \\
\hline 1 & 1987 & 'STH 1' & $10^{*}$ & + & 18.0 \\
\hline 2 & 1987 & ${ }^{\prime}$ Bristol 3' & 25 & - & 4.1 \\
\hline 3 & 1994 & EMRSA-16 & 30 & + & 7.0 \\
\hline 4 & 1993 & EMRSA-16 & 30 & + & 4.1 \\
\hline 5 & 1994 & EMRSA-16 & 30 & + & 7.0 \\
\hline 6 & 1994 & EMRSA-16 & 30 & + & 7.0 \\
\hline 7 & 1994 & EMRSA-16 & 30 & + & 7.0 \\
\hline 8 & 1994 & EMRSA-3 & 30 & + & 7.0 \\
\hline 9 & 1990 & EMRSA-3 & 25 & - & 5.5 \\
\hline 10 & 1993 & OMRSA & 22 & - & 10.0 \\
\hline 11 & 1994 & OMRSA & 25 & + & 7.0 \\
\hline 12 & 1994 & IMRSA & 35 & - & 10.0 \\
\hline 13 & 1994 & IMRSA & 35 & - & 10.0 \\
\hline 14 & 1994 & IMRSA & 35 & - & 10.0 \\
\hline 15 & 1994 & IMRSA & 40 & + & 12.0 \\
\hline 16 & 1994 & IMRSA & 35 & - & 10.0 \\
\hline 17 & 1994 & IMRSA & 35 & - & 7.0 \\
\hline
\end{tabular}

* See text for details. 


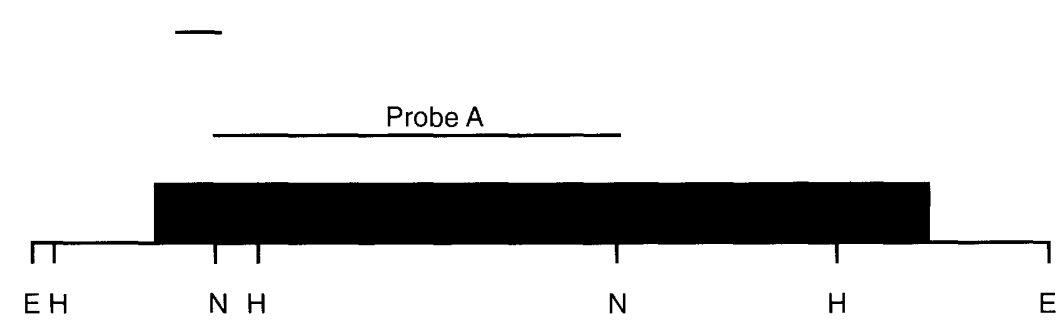

Fig. 1. Schematic representation to show the positions of the open reading frame of mupA (solid block), probes A and $\mathrm{B}$ and restriction sites for EcoRI (E), Hinc II (H) and NcoI (N) on the 4013-bp sequenced fragment [5] of staphylococcal mupirocin resistance plasmid pJ2947.

1.6-kb Nco I fragment of recombinant plasmid pMZ-1. This plasmid consists of a 4.05-kb EcoR I fragment of mupirocin resistance plasmid pJ2947 [4] cloned into Escherichia coli-S. aureus shuttle vector pOX7 [7]. The recombinant plasmid was extracted from the $E$. coli host by alkaline lysis [16] and digested with Nco I (Life Technologies). The resulting $1.6-\mathrm{kb}$ fragment was excised from an agarose $0.8 \%$ gel, purified with a Prep-a-Gene kit (BioRad) and labelled with digoxigenin by random priming. Probe $\mathrm{B}$, which was also intragenic, was generated by PCR and consisted of a 190-bp fragment amplified with forward and reverse primers $m u p A_{\mathrm{F}}\left(5^{\prime}\right.$-TGA CAA TAG AAA AGG ACA GG-3') and $m u p A_{\mathrm{R}}\left(5^{\prime}\right.$-CTC TAA TTC AAC TGG TAA GCC$\left.3^{\prime}\right)$ and equivalent to nucleotide positions 554-743 of the published sequence [5]. Strain 'STH 1' $[10,11]$ was used as the source of template DNA. The method for preparation of template and the amplification conditions were the same as those described previously for amplification of sections of the mecA and 16S rRNA genes of $S$. aureus [17]. All amplifications were achieved with Touchdown (Hybaid) or Genius (Techne) thermal cyclers. Labelling of the 190-bp product was carried out in a second-round PCR reaction to which digoxigenin-11-dUTP was added [18]. Probe A was predicted from sequence data [5] to hybridise with $c$. 1.6-kb Nco I and 2.3-kb Hinc II intragenic fragments of the mupA gene. In contrast, probe B was predicted to hybridise with a Hinc II fragment of $863 \mathrm{bp}$ that extended beyond the $5^{\prime}$ end of the resistance gene (Fig. 1) and was included to provide information about flanking DNA proximal to mupA. Hybridisations with all probes were performed at $68^{\circ} \mathrm{C}$ under stringent conditions as recommended by Boehringer Mannheim.

\section{Amplification of IS257-mupA spacer regions and an internal IS257 fragment}

The spacer regions between mupA and the closest proximal copy of IS257 were amplified with primers mup $A_{\mathrm{R}}$ and IS257 forward primer 1234 (IS257 $7_{\mathrm{F}} ; 5^{\prime}-$ GGC ATG GCG AAA ATC CGT AG). To investigate the presence of a proximal copy of IS257 in the reverse orientation, primer $m u p A_{\mathrm{R}}$ was also used with IS257 reverse primer 1235 (IS257 $; 5^{\prime}$-TGG CGT ATT GAT GAG ACG TAC ATC). Amplification of these spacer regions used cycling conditions described previously [17]. A 407-bp fragment internal to IS257 was amplified with primers 1234 and 1235 , labelled with digoxigenin by PCR as above and used in hybridisation studies to confirm the presence of IS257 sequences in the IS257-mupA spacer regions. The protocol for amplifying this probe fragment consisted of five cycles of $94^{\circ} \mathrm{C}$ for $40 \mathrm{~s}, 55^{\circ} \mathrm{C}$ for $30 \mathrm{~s}, 72^{\circ} \mathrm{C}$ for $30 \mathrm{~s}$, followed by 25 cycles of $92^{\circ} \mathrm{C}$ for $30 \mathrm{~s}, 52^{\circ} \mathrm{C}$ for $30 \mathrm{~s}$ and $72^{\circ} \mathrm{C}$ for $30 \mathrm{~s}$ with a final cycle at $25^{\circ} \mathrm{C}$ for $30 \mathrm{~s}$. The sequences of primers 1234 and 1235 and the amplification conditions for the 407-bp product were kindly provided by Dr W. Grubb [19].

\section{Results}

\section{Plasmids encoding mupirocin resistance}

Initial studies of 15 clinical isolates and two control strains showed that the mupA resistance gene was located on plasmids of variable size in all except control strain 'STH 1' (Table 1). For this particular strain, hybridisation always occurred with DNA that co-migrated with residual chromosomal DNA. A vague band of $c .10 \mathrm{MDa}$ (possibly a plasmid) was visible at this position in some preparations from this strain. In filter mating experiments, high-level mupirocin resistance was transferred readily to $S$. aureus recipient strain WG3358 from nine of the 17 isolates, although transfer frequencies could not be determined with the semi-quantitative method used (Table 1). Importantly, all five isolates of EMRSA-16 tested were able to act as donors in these experiments. One isolate of EMRSA-16 was also resistant to gentamicin but, while mupirocin resistance was carried on an c. $30 \mathrm{MDa}$ plasmid, the aminoglycoside resistance transferred separately on a plasmid of c. $40 \mathrm{MDa}$. Furthermore, mupirocin resistance transferred from this isolate at $c$. 100 -fold greater efficiency than gentamicin resistance (data not shown).

\section{Hybridisation of genomic DNA with mupirocin resistance probes}

Many of the 85 clinical isolates of $S$. aureus used in this study contained plasmids in addition to the 
mupirocin resistance plasmid and, as initial studies indicated that some isolates were unable to transfer mupirocin resistance in vitro (Table 1), it was not possible to overcome this problem by generating transconjugants that contained single plasmids. Hence, direct digestion and comparison of these mupirocin resistance plasmids was not possible. In view of the large number of isolates studied, the location of the mupA gene was therefore investigated further with digests of genomic DNA, the inference being that fragments hybridising with the probe would probably be derived from the resistance plasmids rather than from chromosomal DNA.

The mupA resistance gene was located on seven different sized EcoRI fragments of genomic DNA among the 85 isolates studied. These were designated $\mathrm{A}-\mathrm{G}$ in order of increasing size (Table 2). The patterns of hybridisation observed for control strains 'Bristol 3' (group A) and 'STH 1' (group G) were consistent with the findings of previous studies $[10,11]$. DNA fragments of two sizes accounted for the majority of the isolates; a 7-kb EcoR I fragment in $46(54 \%$; group D) isolates and a fragment of $4.1 \mathrm{~kb}$ in 21 (25\%; group A) isolates (Table 2). Probes A and $\mathrm{B}$ gave identical results with EcoR I-digested DNA. Despite the heterogeneous EcoR I hybridisation patterns, all isolates of all groups had a $1.6-\mathrm{kb}$ Nco I fragment that hybridised with probe A (Fig. 2a); this was consistent with predictions made from sequence data [5]. However, heterogeneity was again observed when Hinc II-digested DNA was hybridised with probe $\mathrm{B}$ (Fig. 2b). This probe was designed to investigate variation in the flanking DNA sequences proximal to mupA and was predicted to hybridise with an 863-bp Hinc II fragment that extended beyond the 5' end of the resistance gene (Fig. 1). However, the actual sizes observed for the Hinc II fragments hybridising with probe $\mathrm{B}$ varied from c. $850 \mathrm{bp}$ to $>10 \mathrm{~kb}$ (Fig. 2b). Bands of $c .850 \mathrm{bp}$ were assumed to correspond to the predicted 863-bp fragment and were obtained from isolates of EcoR I groups A, B and E. Although good correlation was observed between the hybridisation patterns obtained with Hinc II- and EcoR I-digested DNA for isolates of groups A $(4.1-\mathrm{kb}$ EcoR I fragment) and D (7-kb EcoR I fragment), the isolates of other EcoRI groups showed greater diversity in their Hinc II hybridisation patterns.

\section{Variable location of the mupA gene within a strain}

This heterogeneity of EcoR I and Hinc II hybridisation patterns was even observed among epidemiologically unrelated isolates of the same strain (as confirmed by phage typing and pulsed-field gel electrophoresis, data not shown). Two isolates of EMRSA-3 and six isolates of a mecA-negative IMRSA strain had two and four EcoR I hybridisation patterns, respectively (Table 1). Twenty-one isolates of EMRSA-16 had six EcoRI hybridisation patterns (Table 1 and Fig. 3) and, in 16 isolates studied further, this heterogeneity correlated with variations in the digestion pattern of the mupirocin resistance plasmids (Fig. 3).

\section{Preliminary analysis of proximal IS257-mupA spacer regions}

The mupA gene is flanked by direct repeats of IS 257 in diverse isolates of $S$. aureus [7,20]. Hybridisation studies with Hinc II digests and probe B suggested that the variable location of mupA might result from alterations in the flanking DNA proximal to the resistance gene. To explore this possibility further, the study attempted to amplify the spacer region between the closest proximal copy of IS257 and mupA from isolates chosen to represent each of the seven EcoR I hybridisation patterns. Three of these isolates, belonging to hybridisation groups $A, E$ and $G$, yielded amplicons of variable size with primers IS $257_{\mathrm{F}}$ and $m u p A_{\mathrm{R}}$ (Table 2). However, variably sized amplicons were obtained from isolates representing groups $C, D$ and $\mathrm{F}$, when primer $\mathrm{IS} 257_{\mathrm{R}}$ was used with $m u p A_{\mathrm{R}}$.

Table 2. Location of mupA in EcoR I-digested DNA of 85 clinical isolates of high-level mupirocin-resistant $S$. aureus and amplification of proximal flanking DNA

\begin{tabular}{|c|c|c|c|c|}
\hline \multirow{2}{*}{$\begin{array}{l}\text { Pattern } \\
\text { designation }\end{array}$} & \multirow{2}{*}{$\begin{array}{c}\text { EcoR I fragment } \\
\text { bearing mupA } \\
(\mathrm{kb})\end{array}$} & \multirow{2}{*}{$\begin{array}{l}\text { Number of } \\
\text { isolates }\end{array}$} & \multicolumn{2}{|c|}{$\begin{array}{l}\text { Amplification of proximal } \\
\text { IS257-mupA spacer* }\end{array}$} \\
\hline & & & $\mathrm{IS} 257_{\mathrm{F}}+m u p A_{\mathrm{R}}$ & $\mathrm{IS} 257_{\mathrm{R}}+m u p A_{\mathrm{R}}$ \\
\hline A & 4.1 & $21^{\dagger}$ & $2000 \mathrm{bp}$ & - \\
\hline B & 5.5 & 4 & - & - \\
\hline $\mathrm{C}$ & 6.2 & 3 & - & $950 \mathrm{bp}$ \\
\hline$D$ & 7.0 & 46 & - & $950 \mathrm{bp}$ \\
\hline$E$ & 10.0 & 6 & $2000 \mathrm{bp}$ & - \\
\hline $\mathrm{F}$ & 12.0 & 3 & - & $1050 \mathrm{bp}$ \\
\hline G & 18.0 & $2^{+}$ & $1200 \mathrm{bp}$ & - \\
\hline
\end{tabular}

-, No amplicon detected.

* One isolate tested in each category.

${ }^{\dagger}$ Including strain 'Bristol 3'.

Including strain 'STH-1'. 
a

\section{$\begin{array}{llllllll}\lambda & 1 & 2 & 3 & 4 & 5 & 6 & 7\end{array}$}

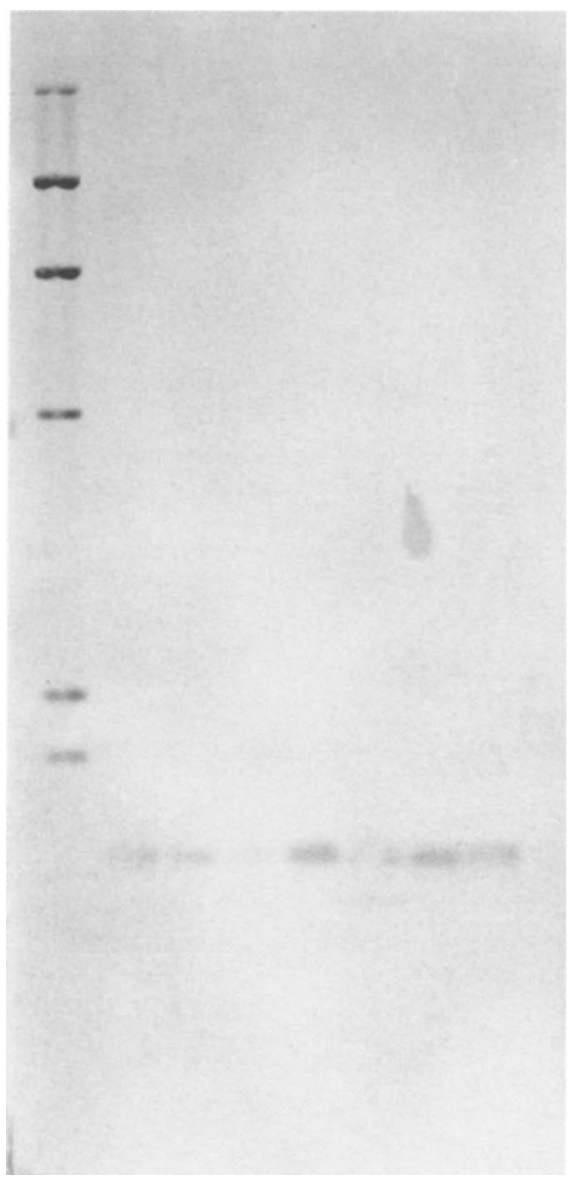

b

Fig. 2. a, Conserved Nco I fragments; b, heterogeneous Hinc II fragments of genomic DNA carrying mupA (hybridisation with probe B) among clinical isolates of high-level mupirocin-resistant $S$. aureus. Lanes 1-7 correspond to isolates of $E c o$ R I groups $\mathrm{A}-\mathrm{G}$, respectively. Hind III digests of phage $\lambda$ DNA are shown as size markers.

Confirmation that these amplicons were indeed spacer regions was checked by hybridisation with both probe B (for mupA) and the IS257 internal probe. No spacer region was amplified with either pair of primers from the tested isolate of pattern group B. Only the c. 2-kb IS257 $7_{\mathrm{F}}-$ mup $_{\mathrm{R}}$ amplicons from isolates of groups A and $\mathrm{E}$ contained internal EcoRI target sites; both yielded two products of $c .1200 \mathrm{bp}$ and $800 \mathrm{bp}$.

\section{Discussion}

In the present study a small panel of clinical isolates were chosen to represent strains causing current problems in UK hospitals to confirm previous reports $[9-11,19]$ that high-level mupirocin resistance (MIC $\geqslant 512 \mathrm{mg} / \mathrm{L}$ ) in $S$. aureus is usually encoded on plasmids that vary both in size and in their ability to transfer on filters to suitable recipient strains. Therefore, it must be inferred that this resistance may also be transferable in vivo to other strains of $S$. aureus. The present study was unable to detect a mupirocin resistance plasmid in control strain 'STH 1', as probes appeared to hybridise with residual chromosomal DNA. This strain has been shown previously to contain an atypical resistance plasmid that co-migrates with chromosomal DNA, but which may be separated by pulsed-field gel electrophoresis [9].

In the 85 isolates studied, the mupA gene was located on seven different $E c o$ R I fragments of genomic DNA, although in most isolates (54\%) it was on a $7-\mathrm{kb}$ fragment. This finding contrasts with all previous large-scale studies of $S$. aureus or coagulase-negative staphylococci [9-11] in which mupA was located on a $4.1-\mathrm{kb} E c o \mathrm{R}$ I fragment in all except two isolates examined; a similar sized fragment was the second most common among the isolates in the present study. Despite the use of digested genomic DNA for hybridisation studies, it was assumed that the DNA fragments carrying mupA were derived from mupirocin resistance plasmids, although the possibility that 


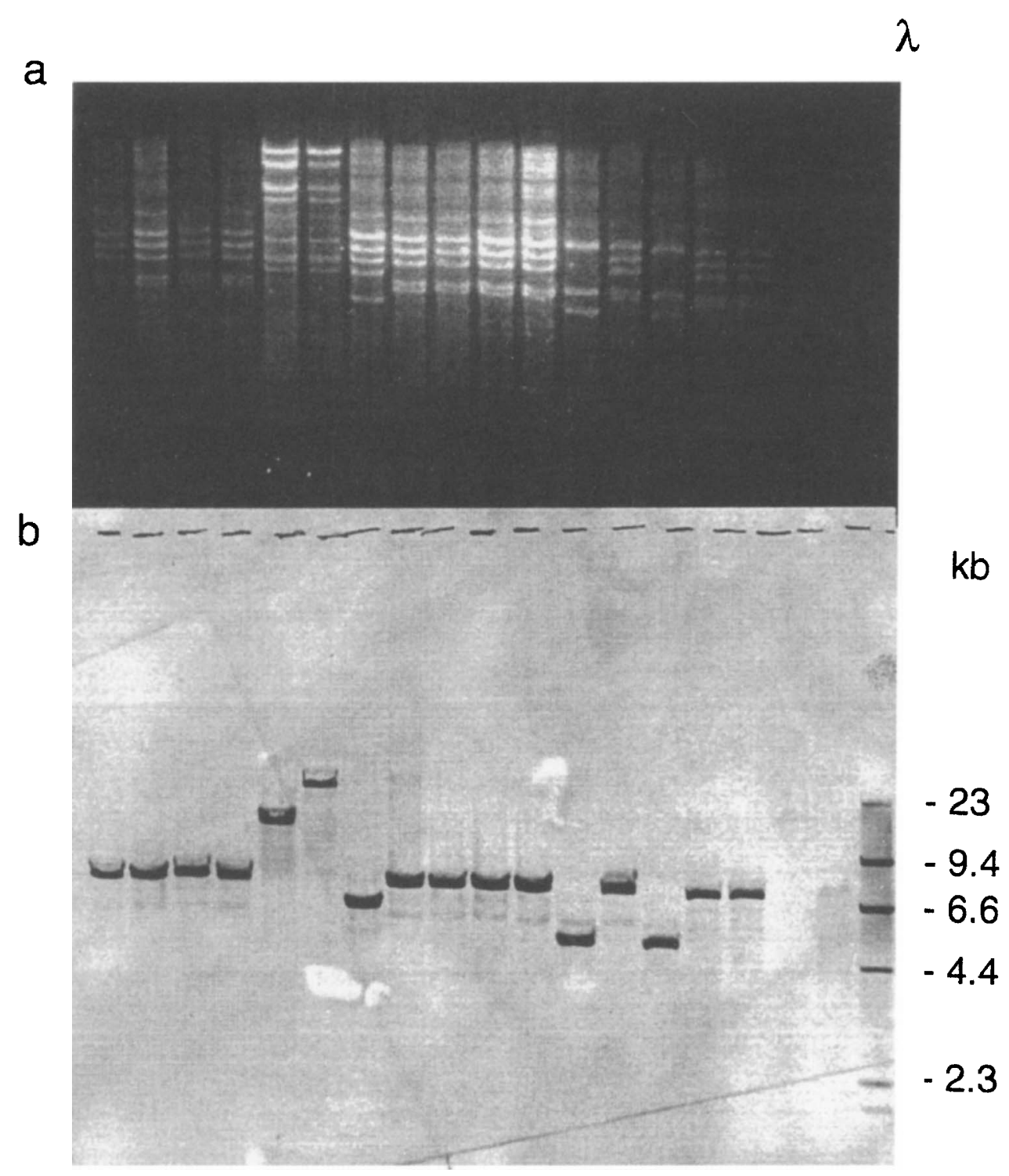

Fig. 3. a, Digestion of mupirocin resistance plasmids from 16 epidemiologically unrelated isolates of EMRSA-16 with $E c o \mathrm{RI}$; b, the corresponding Southern blot hybridised with a mupA probe.

some isolates also possessed chromosomal copies of the mupA gene cannot be excluded. This assumption did not confuse the analysis, because none of the 85 isolates showed two bands of hybridisation - indicating that, if chromosomal and plasmid copies were indeed present in some isolates, both copies must have been located on DNA fragments of identical size. Furthermore, the only isolates of $S$. aureus presently shown to have chromosomal copies of mupA expressed only low-level mupirocin resistance [12]. Interestingly, in this latter study one isolate with high-level resistance and two of three isolates with low-level resistance each had two EcoR I fragments of genomic DNA (4.1 and $>12 \mathrm{~kb}$ ) that hybridised with a mupA probe, but no explanation for this was provided [12]. It should be noted that probes $\mathrm{A}$ and $B$ used in the present study did not react with DNA prepared from $S$. aureus sensitive to mupirocin (MIC $\leqslant 4 \mathrm{mg} / \mathrm{L}$ ), showing low-level resistance (MIC $8-256 \mathrm{mg} / \mathrm{L}$ ) or trained to high levels of resistance
(MIC $\geqslant 512 \mathrm{mg} / \mathrm{L}$ ) by growth on agar containing increasing gradients of mupirocin (data not shown). Furthermore, primers $m u p A_{\mathrm{F}}$ and $m u p A_{\mathrm{R}}$ described herein have been used routinely in this laboratory since April 1996 to detect the mupA gene in staphylococci, combined in the multiplex assay for mecA and 16S RNA described previously [17]. To date, mир $A$ has not been detected in any isolates showing low-level mupirocin resistance. Taken together, these data do not support the recent suggestion that $S$. aureus isolates showing high- and low-level mupirocin resistance differ only in the location (plasmid versus chromosomal) or copy number of mupA [12].

In the present study, the heterogeneous location of mupA was also indicated by Hinc II-digested DNA, although a conserved $\mathrm{Nco}$ I fragment was present in all isolates. As the two $\mathrm{NCO}$ I target sites are intragenic (Fig. 1), these data suggest that mupA itself may be 
conserved. However, as the EcoR I and Hinc II fragments predicted to hybridise with the probes extend beyond the mupA open reading frame, it seemed probable that the variation might result from alterations in the flanking DNA proximal to the resistance gene. Although the heterogeneity might have resulted from mutations affecting EcoRI and Hinc II target sites, mupA has been shown to be flanked by direct repeats of IS257 (which has no internal EcoR I or Hinc II target sites) and recombination $[7,19]$ or transposition [20] events involving these elements could also account for the differences. By amplifying the spacer regions, this study has shown that the copy of IS257 proximal to mupA can be present in either orientation and that the sizes of these spacer regions (with IS257 in either orientation) vary; a further indication of proximal heterogeneity. On the basis of these observations it is suggested that IS257mediated events are responsible, at least in part, for the variable location of mupA in $S$. aureus. The molecular basis for the heterogeneity observed requires further detailed characterisation and studies are under way to sequence the flanking DNA proximal to mupA in selected isolates. Further hybridisation studies with new probes, amplification of mupA-IS257 spacer regions and sequencing are also necessary to determine whether these isolates show similar heterogeneity in the flanking DNA distal to mupA.

It is tempting to speculate that the variable location of mupA in epidemiologically unrelated isolates of certain strains of $S$. aureus might warrant evaluation as an epidemiological tool. Although high-level mupirocin resistance is present in diverse strains of $S$. aureus, its emergence in EMRSA-16 has caused particular problems. This epidemic strain is currently causing major infection control problems in many UK hospitals [3]. High-level mupirocin resistance was readily transferable in vitro from each of five EMRSA-16 isolates used in mating experiments in this study, which suggests that it will become far more widely disseminated in the future, mediated both by the spread of resistant EMRSA-16 and also by the horizontal transmission of resistance to other staphylococci, including MRSA. mupA was found on six different DNA fragments in isolates of EMRSA-16, and these differences correlated with variations in the digestion pattern of the mupirocin resistance plasmids. Hence, although the low numbers of EMRSA-16 isolates in this study did not permit correlation between fragment size and geographical area, this heterogeneity could potentially be used to monitor the dissemination of high-level mupirocin resistance within EMRSA-16 and other strains of $S$. aureus.

We thank K. Dyke (University of Oxford) who kindly supplied recombinant plasmid pMZ-1; and $\mathrm{K}$. Dyke and Dr W. Grubb (University of Perth) for their advice and help with amplification of IS 257. Part of this work was presented at the 8th International
Symposium on Staphylococci and Staphylococcal Infections, Aix-lesBains, France, June 1990.

\section{References}

1. Gilbart J, Perry CR, Slocombe B. High-level mupirocin resistance in Staphylococcus aureus: evidence for two distinct isoleucyl-tRNA synthetases. Antimicrob Agents Chemother 1993; 37: 32-38.

2. Rahman M, Noble WC, Cookson B. Mupirocin-resistant Staphylococcus aureus. Lancet 1987; 2: 387.

3. Marples RR, Speller DCE, Cookson BD. Prevalence of mupirocin resistance in Staphylococcus aureus. J Hosp Infect 1995; 29: 153-155.

4. Dyke KGH, Curnock SP, Golding M, Noble WC. Cloning of the gene conferring resistance to mupirocin in Staphylococcus aureus. FEMS Microbiol Lett 1991; 77: 195-198.

5. Hodgson JE, Curnock SP, Dyke KGH, Morris R, Sylvester DR, Gross MS. Molecular characterization of the gene encoding high-level mupirocin resistance in Staphylococcus aureus J2870. Antimicrob Agents Chemother 1994; 38: 1205-1208.

6. Bradley SF, Ramsey MA, Morton TM, Kauffman CA. Mupirocin resistance: clinical and molecular epidemiology. Infect Control Hosp Epidemiol 1995; 16: 354-358.

7. Needham C, Rahman M, Dyke KGH, Noble WC. An investigation of plasmids from Staphylococcus aureus that mediate resistance to mupirocin and tetracycline. Microbiology 1994; 140: 2577-2583.

8. Slocombe B, Perry S. The antimicrobial activity of mupirocin - an update on resistance. $J$ Hosp Infect 1991; 19(Suppl B): $19-25$

9. Rahman M, Connolly S, Noble WC, Cookson B, Phillips I. Diversity of staphylococci exhibiting high-level resistance to mupirocin. J Med Microbiol 1990; 33: 97-100.

10. Connolly S, Noble WC, Phillips I. Mupirocin resistance in coagulase-negative staphylococci. $J$ Med Microbiol 1993; 39: $450-453$.

11. Rahman M, Noble WC, Dyke KGH. Probes for the study of mupirocin resistance in staphylococci. J Med Microbiol 1993; 39: $446-449$.

12. Ramsey MA, Bradley SF, Kauffman CA, Morton TM. Identification of chromosomal location of mupA gene encoding low-level mupirocin resistance in staphylococcal isolates. Antimicrob Agents Chemother 1996; 40: 2820-2823.

13. Townsend DE, Ashdown N, Bolton S, Grubb WB. The use of cetyltrimethylammonium bromide for the rapid isolation from Staphylococcus aureus of relaxable and non-relaxable plasmid DNA suitable for in vitro manipulation. Lett Appl Microbiol 1985; 1: 87-94

14. Richards J, Williams H, Warner M et al. Nosocomial spread of Staphylococcus aureus showing intermediate resistance to methicillin. J Hosp Infect 1993; 25: 91-96.

15. Pitcher DG, Saunders NA, Owen RJ. Rapid extraction of bacterial genomic DNA with guanidium thiocyanate. Lett Appl Microbiol 1989; 8: 151-156.

16. Woodford N, Morrison D, Cookson B, George RC. Comparison of high-level gentamicin-resistant Enterococcus faecium isolates from different continents. Antimicrob Agents Chemother 1993; 37: $681-684$.

17. Bignardi GE, Woodford N, Chapman A, Johnson AP, Speller DCE. Detection of the mec-A gene and phenotypic detection of resistance in Staphylococcus aureus isolates with borderline or low-level methicillin resistance. J Antimicrob Chemother 1996; 37: $53-63$.

18. Woodford N, Morrison D, Johnson AP, Briant V, George RC, Cookson B. Application of DNA probes for rRNA and vanA genes to investigation of a nosocomial cluster of vancomycin-resistant enterococci. J Clin Microbiol 1993; 31: $653-658$.

19. Morton TM, Johnston JL, Patterson J, Archer GL. Characterization of a conjugative staphylococcal mupirocin resistance plasmid. Antimicrob Agents Chemother 1995; 39: 1272-1280.

20. Needham C, Noble WC, Dyke KGH. The staphylococcal insertion sequence IS257 is active. Plasmid 1995; 34: 198-205. 